\title{
Alumina sulfuric acid (ASA), tungstate sulfuric acid (TSA), molybdate sulfuric acid (MSA) and xanthan sulfuric acid (XSA) as solid and heterogeneous catalysts in green organic synthesis: a review
}

\author{
Rajesh H. Vekariya and Hitesh D. Patel * \\ Department of Chemistry, School of Sciences, Gujarat University, Ahmedabad, Gujarat, India \\ E-mail: drhiteshpatel1@gmail.com
}

DOI: $\underline{\text { http://dx.doi.org/10.3998/ark.5550190.p008.894 }}$

\begin{abstract}
In this comprehensive review, we report on the sulfonic acid functionalized solid acids such as alumina sulfuric acid (ASA), tungstate sulfuric acid (TSA), molybdate sulfuric acid (MSA) and xanthan sulfuric acid (XSA) as green and heterogeneous catalysts in a wide range of organic transformations. Recently, the use of sulfonic acid functionalized solid acids as catalyst in organic synthesis has become an efficient and green strategy for the selective construction of organic motifs. The sustainable advantage of sulfonic acid functionalized solid acids is that it can be recovered and reused several times without loss of their efficiency. In this review, we attempt to give an overview of the use of ASA, TSA, MSA, XSA as catalysts in the synthesis of various organic compounds having industrial as well as pharmaceutical applications.
\end{abstract}

Keywords: Alumina sulfuric acid, tungstate sulfuric acid, molybdate sulfuric acid, xanthan sulfuric acid, heterogeneous catalysts, solid acid catalyst

\section{Table of Contents}

1. Introduction

2. Alumina Sulfuric Acid (ASA)

2.1. Synthesis of benzimidazoles and quinoxalines

2.2. Nitration of aromatic compounds

2.3. Synthesis of 2,5-disubstituted 1,3,4-oxadiazoles

2.4. Chemoselective dithioacetalization and oxathioacetalization

2.5. ortho-Silylation of alcohols, oximes and phenols

2.6. Biginelli type condensation reaction

2.7. Pechmann condensation reaction

2.8. Synthesis of xanthenedione derivatives 
2.9. Synthesis of 1,4-dihydropyridines

2.10. Strecker reaction

3. Tungstate Sulfuric Acid (TSA)

3.1. Synthesis of $\alpha$-substituted $\beta$-naphthols derivatives

3.2. Synthesis of benzoxazoles and benzothiazoles

3.3. Biginelli condensation reaction

3.4. Rapid deoximation of oximes

3.5. Synthesis of 1,3-dithiane and 1,3-dithiolane derivatives

3.6. Oxidation of thiols to disulfides and oxidative demasking of 1,3-dithianes

3.7. N-Nitrosation of secondary amines

3.8. Synthesis of benzimidazoles

3.9. Synthesis of polycyclic aromatic phenazines and quinoxalines

3.10. Synthesis of calicx[4]resorcinarene derivatives

4. Molybdate Sulfuric Acid (MSA)

4.1. Synthesis of 2,3,4,5-tetrasubstituted pyrroles

4.2. Synthesis of gem-bisamide

4.3. Synthesis of disulfides

4.4. Synthesis of quinoxaline and phenazine derivatives

4.5. Synthesis of N-nitroso compounds

5. Xanthan Sulfuric Acid (XSA)

5.1. Synthesis of bis(indolyl)methane derivatives

5.2. Synthesis of N-substituted pyrroles

5.3. Pechmann condensation reaction

5.4. Synthesis of 4,4'-(arylmethylene)bis(1H-pyrazol-5-ols)

5.5. Synthesis of 14-Aryl-14H-dibenzo[a,i]xanthene-8,13-dione

5.6. Synthesis of $\alpha$-amino phosphonates

5.7. Biginelli condensation reaction

5.8. Synthesis of $\alpha$-amino nitriles

6. Conclusions

7. Acknowledgements

8. References

\section{Introduction}

Organic synthesis generally involves the use of various solvents and catalysts, which may be toxic, hazardous, corrosive and inflammable. These chemical processes are largely harmful to the environment. Nowadays, it has become a major issue that has been brought forward at the global level. Apart from the atmospheric pollution, the use of solvents in an industrial process may also cause occupational health hazards. Furthermore, completion of the reaction, some reagents or catalysts, which are used in many chemical processes, are converted into another 
form and are not recycled efficiently. In view of the seriousness of chemical pollution, the use of a wide range of volatile, toxic, corrosive and inflammable chemicals are being re-examined, leading to a search for the design and development of environmentally benign green organic transformations.

According to the green chemistry principles, ${ }^{1}$ modern organic synthesis should be carried out using methodologies that maximize conversion of reactants into products, generate low amounts of waste or by-products as far as possible, utilize minimum energy requirements, and reduce the use of toxic, corrosive and hazardous chemicals.

Nowadays, organic transformations by using solid, heterogeneous and reusable catalysts have been developed, because of environmental and economic regulations. ${ }^{2-6}$ Homogeneous catalysts such as sulfuric acid $\left(\mathrm{H}_{2} \mathrm{SO}_{4}\right)$, hydrofluoric acid (HF), hydrobromic acid ( $\left.\mathrm{HBr}\right)$, hydrochloric acid $(\mathrm{HCl})$ and tri-fluoroacetic acid $\left(\mathrm{CF}_{3} \mathrm{COOH}\right)$ are frequently used in organic synthesis. ${ }^{7}$ However, these acid catalysts are toxic, harmful, corrosive and difficult to handle. Also, their disposals cause the problems for the chemical industries. ${ }^{8}$ In the case of homogeneous catalysts recovery and separation of the catalyst from the reaction mixture is very difficult. ${ }^{9}$ In addition, during the reaction or work-up process, loss of catalyst is a significant problem in many organic transformations. If a recyclable heterogeneous catalyst and solvent free conditions are used for many organic transformations, then both ecological and economic profiles will improve. Therefore, in recent years more development has been carried out in the field of heterogeneous solid acids catalyzed organic synthesis. ${ }^{10-19}$ Solid heterogeneous acids have many advantages over conventional acids such as simplicity in handling, decreased reactor and plant corrosion problems and reusability. Also, wastages and by-products can be minimized. ${ }^{20-23}$

Development of novel heterogeneous catalysts to facilitate various organic transformations is an intense area of research in recent years. Therefore, many efforts have been made by scientists constantly to introduce new and novel heterogeneous catalyzed organic synthesis by using alumina sulfuric acid (ASA), tungstate sulfuric acid (TSA), molybdate sulfuric acid (MSA) and xanthan sulfuric acid (XSA) (Figure 1), which are more efficient, economical and compatible with the environment. Also, these catalysts can be recovered and reused many times, without decreasing their activity. The present article is intended to review briefly the recent research progress made concerning the synthesis of different organic compounds catalyzed by heterogeneous solid acids.

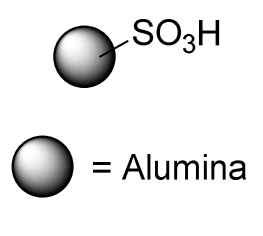

ASA

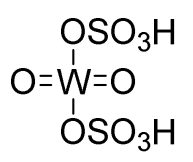

TSA

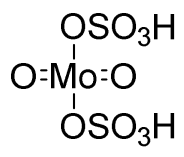

MSA

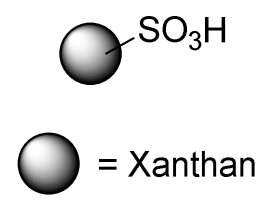

XSA

Figure 1. Structure of ASA, TSA, MSA, XSA. 


\section{Alumina Sulfuric Acid (ASA)}

Alumina sulfuric acid (ASA) has been developed as a solid Bronsted acid catalyst for the synthesis of a variety of organic and heterocyclic compounds. ASA can be readily prepared by adding chlorosulfonic acid $(0.35 \mathrm{~mL}, 5.25 \mathrm{mmol})$ to activated neutral alumina $(15 \mathrm{~g})$ under stirring condition with removal of the liberated $\mathrm{HCl}$ gas under reduced pressure. Then the reaction was kept at this condition for $1 \mathrm{~h}$ at room temperature, washed successively with water, followed by ethanol and dried at $130{ }^{\circ} \mathrm{C}$ for $3 \mathrm{~h} .{ }^{24-26} \mathrm{ASA}$ is a white solid which can be stored for a long period of time without a decrease in activity.

ASA is a solid, heterogeneous catalyst and after completion of an organic transformation, it can be recovered and reused several times without loss of efficiency.

\subsection{Synthesis of benzimidazoles and quinoxalines}

Pramaniket et al. ${ }^{27}$ have developed an efficient and eco-friendly synthesis of 2-aryl-1-arylmethyl$1 H$-benzimidazoles via the condensation of different aldehydes with ortho-phenylenediamine in the presence of alumina sulfuric acid (ASA) as a recyclable solid, heterogeneous acid catalyst in ethanol at room temperature (Scheme 1a). The effects of various solvents such as ethanol, nhexane, diethyl ether, ethyl acetate, dichloromethane, methanol, water and toluene have also been studied by the authors. However, the reactions using ethanol gave the best yield of the products. In addition, the authors also carried out a comparison of ASA with different acid catalysts such as $\mathrm{HClO}_{4}-\mathrm{SiO}_{2}$, PPA (polyphosphorous acid) $-\mathrm{SiO}_{2}, \mathrm{NaHSO}_{4}-\mathrm{SiO}_{2}, \mathrm{Al}_{2} \mathrm{O}_{3}$, Zeolite and Conc. $\mathrm{H}_{2} \mathrm{SO}_{4}$. It was found that these acids did not give good results as compared to ASA. Also, the ASA could be recovered after completion of the reaction, while homogeneous catalysts couldn't be recovered. The authors have also reported the synthesis of quinoxaline from orthophenylenendiamine and 1,2-diketone in the presence of ASA in ethanol at room temperature, which afforded high yield of the product (Scheme 1b).

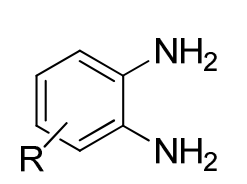

(1 mmol)

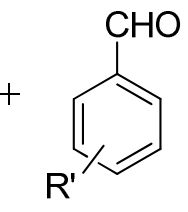

(2 mmol)

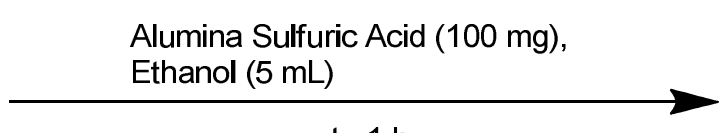

r.t., $1 \mathrm{~h}$

$$
\begin{aligned}
& \mathrm{R}=\mathrm{H}, \mathrm{Me} \\
& \mathrm{R}^{\prime}=\mathrm{H}, \mathrm{Me}, \mathrm{OMe}, \mathrm{NO}_{2}, \mathrm{Cl}, \mathrm{OH}, \text { pyridyl, furyl }
\end{aligned}
$$

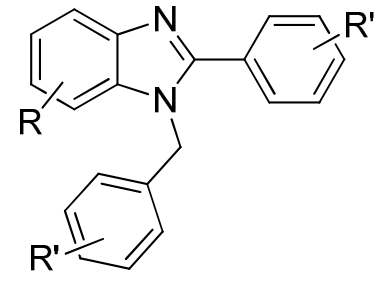

$77-91 \%$

Scheme 1a. Synthesis of benzimidazole derivatives catalyzed by ASA. 
<smiles>[R]Oc1cccc(N)c1N</smiles>

$(1 \mathrm{mmol})$<smiles>c1ccc(-c2nc3ccccc3nc2-c2ccccc2)cc1</smiles>

95-97\%

OR<smiles>c1ccc(C2=NC3CCCCC3N=C2c2ccccc2)cc1</smiles>

$98 \%$

Scheme 1b. Synthesis of quinoxaline derivatives catalyzed by ASA.

\subsection{Nitration of aromatic compounds}

Hosseini-Sarvari et al. $^{28}$ have discovered a novel and safe protocol for nitration of phenols, anilines and other aromatic compounds in the presence of alumina sulfuric acid (ASA) as a catalyst and $\mathrm{Mg}\left(\mathrm{NO}_{3}\right)_{2} \cdot 6 \mathrm{H}_{2} \mathrm{O}$ as a nitrating agent in neat water as a solvent (Scheme 2). With this protocol nitrated products were obtained in excellent yields. In a comparative study, the authors employed this reaction using toluene or dichloromethane (DCM) under reflux conditions; however, in such cases the reaction proceeded with low yield. In addition, no products were obtained when the reaction was carried out at room temperature or without water or catalyst. Different metal nitrates have alse been employed in this reaction, but $\mathrm{Mg}\left(\mathrm{NO}_{3}\right)_{2} \cdot 6 \mathrm{H}_{2} \mathrm{O}$ gave the best results as compare to others. It is interesting to note that in the presence of ASA, the amino group was protonated and therefore acted as a deactivating group. Furthermore, di-nitration and tri-nitration of phenol was also carried out by the authors. The use of water as a solvent makes this method green and clean.

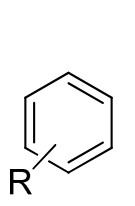

(1 mmol)

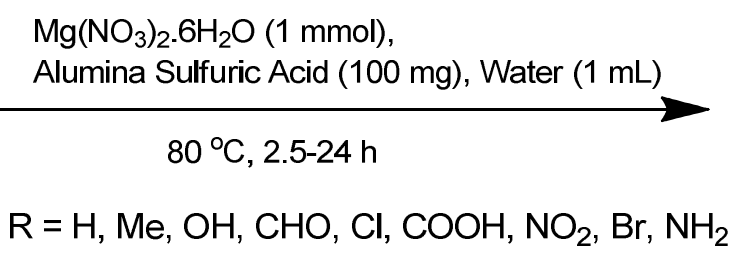

$75-95 \%$

Scheme 2. Nitration of aromatic compounds catalyzed by ASA.

\subsection{Synthesis of 2,5-disubstituted 1,3,4-oxadiazoles}

Teimouri and co-workers ${ }^{29}$ have disclosed an efficient method for the synthesis of 2,5disubstituted 1,3,4-oxadiazoles by the condensation of different aromatic carboxylic acids and benzoyl hydrazides in the presence of natural alumina, alumina sulfuric acid (ASA), nanoalumina and nano-alumina sulfuric acid (nano-ASA) as a solid heterogeneous catalyst. These reactions were performed under microwave irradiation (dedicated microwave oven) and solvent- 
free conditions (Scheme 3). Shorter process times, easy work-up process, mild reaction conditions, and high yields of the products are the advantages of this protocol. Here, microwave irradiation considerably decreased the reaction times and increased the yield of the products as compared to the conventional methods. In addition, the product was obtained in very low amount when catalyst was not used in this reaction. The authors have carried out this reaction with various alumina based catalysts such as natural alumina, nano- $\gamma$-alumina, ASA and nano- $\gamma$-ASA. However, the nano- $\gamma$-ASA showed the best activity in this synthesis. Higher yield of the products and recoverability of catalyst make this method green and an environmentally friendly.<smiles>NNC(=O)c1ccccc1</smiles>

$(1 \mathrm{mmol})$

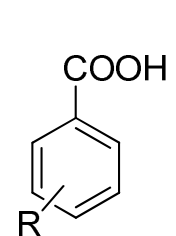

$(1 \mathrm{mmol})$
A) Nutral Alumina (15 mg)

OR

B) Nano-Alumina (15 mg)

OR

C) Alumina Sulfuric Acid (15 mg)

OR

D) Nano-Alumina Sulfuric Acid (15 mg)

$90^{\circ} \mathrm{C}, \mathrm{MWI}(600 \mathrm{~W}), 15 \mathrm{~min}$

$\mathrm{R}=\mathrm{H}, \mathrm{Me}, \mathrm{OMe}, \mathrm{NO}_{2}, \mathrm{Cl}, \mathrm{Br}$

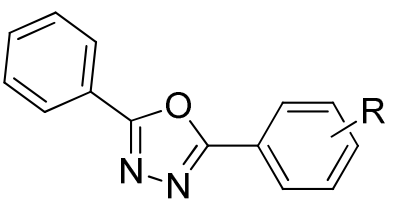

A) $60-64 \%$ C) $84-90 \%$

B) $67-72 \%$ D) $90-96 \%$

Scheme 3. Synthesis of 2,5-disubstituted 1,3,4-oxadiazoles catalyzed by ASA.

\subsection{Chemoselective dithioacetalization and oxathioacetalization}

Shaterian et al. $^{30}$ have described an efficient and green synthesis of dithiolane, dithiane, and oxathiolane derivatives from their corresponding carbonyl compounds using a catalytic amount of alumina sulfuric acid (ASA) in acetonitrile at room temperature (Scheme 4). Protection of aldehydes in the presence of ketones was selectively carried out by this protocol. The authors synthesized 2-phenyl-1,3-dithiane using benzaldehydes and 1,3-propanedithiol in the presence of different amounts of ASA as a catalyst under various of solvents, such as diethyl ether, dichloromethane, chloroform, ethyl acetate and acetonitrile. However, the best result was obtained in acetonitrile with $50 \mathrm{mg}$. of ASA.

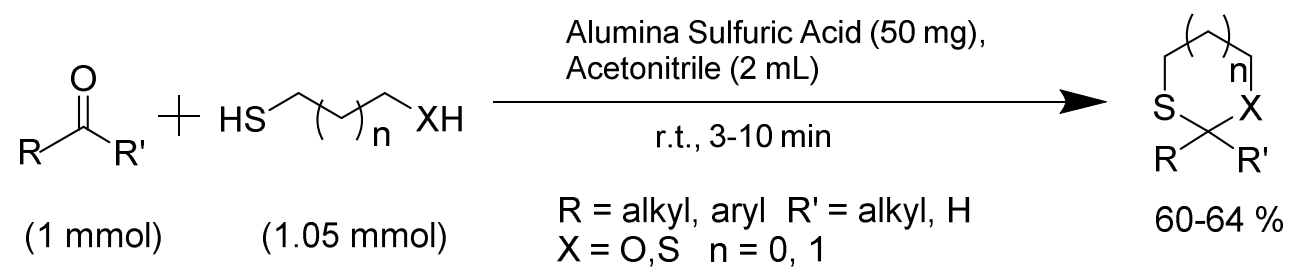

Scheme 4. Chemoselective dithioacetalization and oxathioacetalization catalyzed by ASA. 


\section{5. ortho-Silylation of alcohols, oximes and phenols}

Shaterian et al. ${ }^{31}$ have developed ortho-Silylation of a wide range of alcohols, phenols and oximes in the presence of hexamethyldisilazane (HMDS) at room temperature, which afforded high yields of the products (Scheme 5). The primary alcohols were converted selectively into their corresponding ortho-silylated products in the presence of secondary and tertiary alcohols. In a comparative study, authors carried out this reaction with various catalysts such as lithium perchlorate, iodine and cupric sulfate pentahydrate. However, the reactions using ASA gave the best product yields.

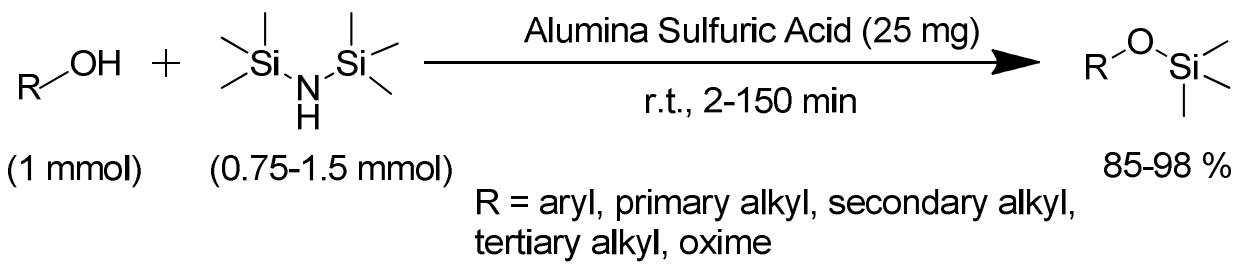

Scheme 5. ortho-Silylation of alcohols, oximes and phenols catalyzed by ASA.

\subsection{Biginelli type condensation reaction}

Shaterian and co-workers ${ }^{32}$ have discovered an efficient and green procedure for the synthesis of substituted dihydropyrimidinones/thiones derivatives through the condensation of various aldehydes and 1,3-diketo compounds with urea or thiourea using alumina sulfuric acid (ASA) as a recyclable catalyst under microwave irradiation (domestic microwave oven, samsung, model KE300R) in short periods of time (Scheme 6). In addition, by this protocol a wide range of multi-substituted 3,4-dihydropyrimidinones/thiones derivatives were synthesized. Thus, this method is considered to have a wide synthetic utility. In addition, Besoluk et al. ${ }^{33}$ have also developed the same protocol for the synthesis of substituted dihydropyrimidinones/thiones derivatives in excellent yield in the presence of alumina sulfuric acid as a reusable catalyst. Compare to conventional acid catalysts, ASA gave the best results and could be easily recovered and reused.

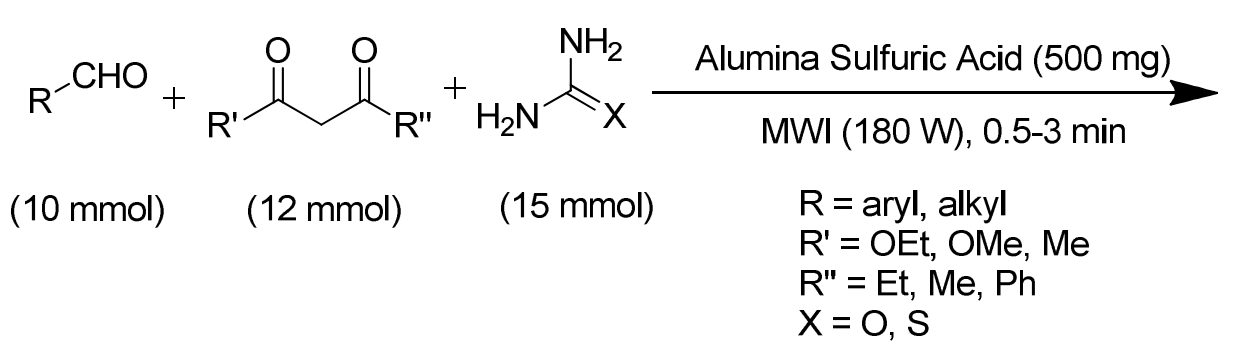<smiles>[R]C(=O)C1=C([R])NC([X])NC1[R]</smiles>
$67-93 \%$

Scheme 6. Biginelli type condensation reaction catalyzed by ASA. 


\subsection{Pechmann condensation reaction}

Amoozadeh et al. ${ }^{34}$ have discovered high yielding methodology for the synthesis of coumarin derivatives through the Pechmann condensation reaction using alumina sulfuric acid (ASA) under solvent-free condition at $100{ }^{\circ} \mathrm{C}$ (Scheme 7). In a comparative study, the authors carried out this reaction with various catalysts, such as ASA, neutral alumina, acidic alumina, $\mathrm{Al}_{2} \mathrm{O}_{3} / \mathrm{H}_{3} \mathrm{PO}_{4}, \mathrm{Al}_{2} \mathrm{O}_{3} / \mathrm{HNO}_{3}, \mathrm{Al}_{2} \mathrm{O}_{3} / \mathrm{H}_{2} \mathrm{SO}_{4}, \mathrm{Al}_{2} \mathrm{O}_{3} / \mathrm{HClO}_{4}$ and $\mathrm{H}_{2} \mathrm{SO}_{4}$. However, the reactions using ASA gave the best product yields. Furthermore, 4-methyl-2H-benzo[ $h]$ chromen-2-one could be efficiently synthesized from naphthol-1-ol.

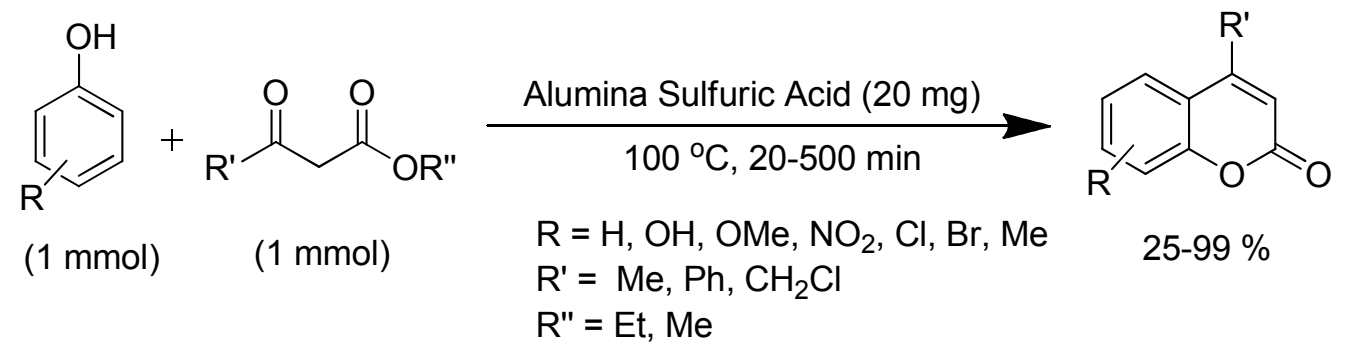

Scheme 7. Pechmann condensation reaction catalyzed by ASA.

\subsection{Synthesis of Xanthenedione derivatives}

Pramanik and co-workers ${ }^{35}$ have developed a green synthesis of 9-aryl-1,8dioxododecahydroxanthenes and 9-aryl-3,3,6,6-tetramethyl-1,8-dioxooctahydroxanthenes in high yield, through the chemoselective cyclocondensation of various aryl and heteroaryl aldehydes with 1,3-diketones using alumina sulfuric acid (ASA) as a recyclable catalyst. All reactions were carried out in ethanol under reflux condition (Scheme 8). In a comparative study, the authors carried out this reaction with various acidic catalysts such as ASA, conc. $\mathrm{H}_{2} \mathrm{SO}_{4} /$ alumina, neutral alumina, cellulose sulfuric acid (CSA), conc. $\mathrm{H}_{2} \mathrm{SO}_{4}, \quad \mathrm{SiO}_{2}, \mathrm{PPA}-\mathrm{SiO}_{2}, \quad \mathrm{HClO}_{4} / \mathrm{SiO}_{2}$, $\mathrm{NaHSO}_{4} / \mathrm{SiO}_{2}$ and $\mathrm{NaCl} /$ alumina. However, the high yield and selectivity of products were observed in the case of ASA. Various organic solvents such as hexane, diethyl ether, tetrahydrofuran (THF), Acetone, ethyl acetate, methanol, dichloromethane (DCM), 1-propanol and water were also employed in this reaction, but they did not give the best results as compared to ASA. By this protocol, a wide range of xanthenedione derivatives was synthesized in high yield.

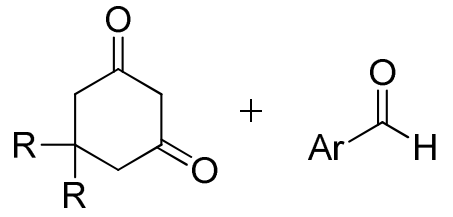

(2 mmol)
(1 $\mathrm{mmol})$
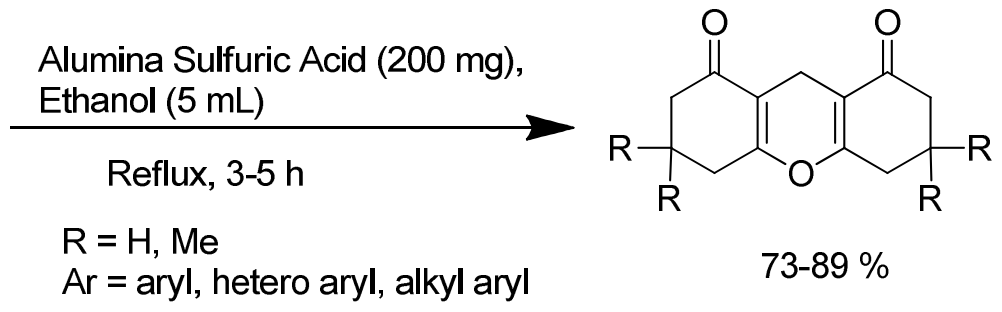

$73-89 \%$

Scheme 8. Synthesis of xanthenedione derivatives catalyzed by ASA. 


\subsection{Synthesis of 1,4-dihydropyridines}

Arslan and co-workers ${ }^{36}$ have described a multi-component condensation of various aldehydes, 1,3-dicarbonyl compounds and ammonium acetate for the synthesis of 1,4-dihydropyridines in excellent yield using alumina sulfuric acid (ASA) as a catalyst in methanol under reflux condition (Scheme 9). The yields of the products and time of the reaction depended on the type of reagent used in this reaction. Instead of ethyl acetoacetate, dimedone shows good results due to the acidity of the methylenic protons. In addition, substrates containing electron-withdrawing and electron-releasing groups undergo reaction smoothly in this transformation.

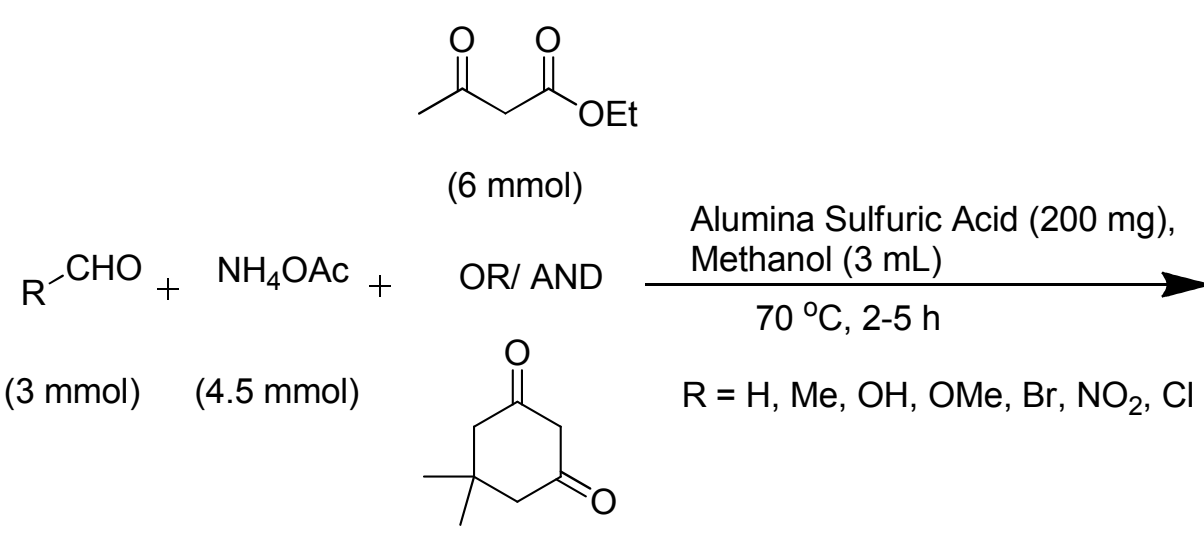

(6 mmol)<smiles>[R]C1C(C(=O)OCC)=C(C)NC(C)=C1C(=O)OCC</smiles>

$82-89 \%$

OR/ AND<smiles>[R]C1C(C(=O)OCC)=C(C)NC2=C1C(=O)CC(C)(C)C2</smiles>

$87-95 \%$

Scheme 9. Synthesis of 1,4-dihydropyridines catalyzed by ASA.

\subsection{Strecker reaction}

Teimouri et al. $^{37}$ have discovered a condensation of different aldehydes, amines and trimethylsilyl cyanides for the synthesis of $\alpha$-aminonitriles derivatives using natural alumina, alumina sulfuric acid (ASA), nano- $\gamma$-alumina, nano-alumina sulfuric acid (nano-ASA) (Scheme 10). All these reactions were performed under microwave irradiation (dedicated microwave oven) without the use of any organic solvents. The authors have described and compared the catalytic activity of natural alumina, ASA, nano- $\gamma$-alumina, and nano-ASA, and it was found that, nano-ASA showed better activity in terms of the yield of the products and time of the reaction. The temperature and the MWI power played important roles in this reaction. At higher or lower temperatures, the reaction rate was decreased. 
<smiles>[R][R]1cccc(C=O)c1</smiles>

(1 mmol) (1 mmol)<smiles>Nc1ccc([18F])cc1</smiles>

$(1.5 \mathrm{mmol})$

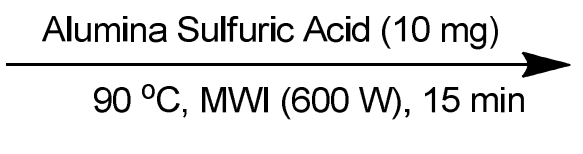

$\mathrm{R}=\mathrm{H}, \mathrm{Me}, \mathrm{OH}, \mathrm{OMe}, \mathrm{Cl}, \mathrm{NO}_{2}$ $\mathrm{R}^{\prime}=\mathrm{H}, \mathrm{Br}$

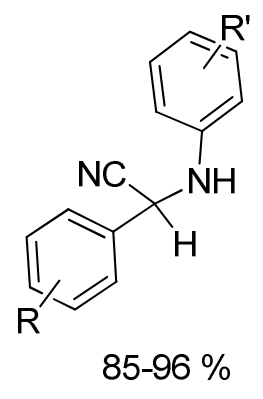

Scheme 10. Strecker reaction catalyzed by ASA.

\section{Tungstate Sulfuric Acid (TSA)}

TSA is a yellow colored solid, heterogeneous catalyst, which decomposed at $285{ }^{\circ} \mathrm{C}$. For the preparation of TSA, take $n$-hexane $(25 \mathrm{~mL})$ in a $100 \mathrm{~mL}$ round-bottomed flask, equipped with an ice bath, and $0.59 \mathrm{~g}(2.0 \mathrm{mmol})$ of anhydrous sodium tungstate was added. To the stirred mixture, $0.266 \mathrm{~mL}(4.0 \mathrm{mmol})$ of chlorosulfonic acid was added drop wise during $30 \mathrm{~min}$. This solution was stirred for $1.5 \mathrm{~h}$ and the reaction mixture was cautiously poured into $25 \mathrm{~mL}$ of chilled distilled water with agitation. The yellow solid which separated was filtered and the catalyst was washed with distilled water 5 times or until the filtrate showed a negative test for the chloride ion, and dried at $120{ }^{\circ} \mathrm{C}$ for 5 h. ${ }^{38,39}$ It can be stored indefinitely without loss of their efficiency.

TSA is a recyclable, nonhygroscopic and eco-friendly catalyst and can be reused several times without the loss of activity.

\subsection{Synthesis of $\alpha$-substituted $\beta$-naphthols derivatives}

Kamaei et al. ${ }^{40}$ have disclosed an efficient and solvent-free synthesis of $\alpha$-substituted $\beta$-naphthols using tungstate sulfuric acid (TSA) at $100{ }^{\circ} \mathrm{C}$ in a short period of time (Scheme 11). This ecofriendly method has some advantages such as excellent yields, less reaction time, use of recyclable catalyst, and easy work-up. 


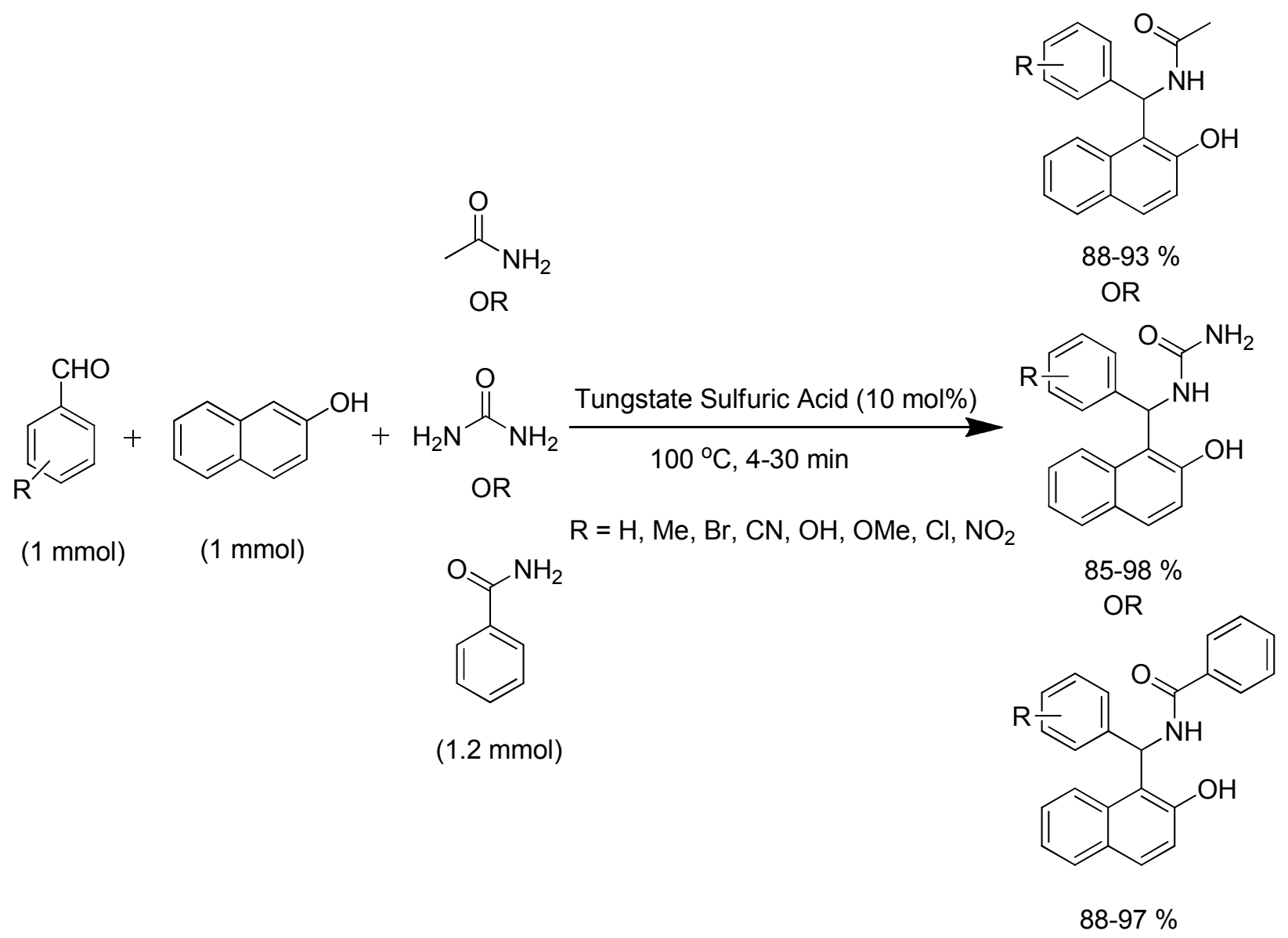

Scheme 11. Synthesis of $\alpha$-substituted $\beta$-naphthols derivatives catalyzed by TSA.

\subsection{Synthesis of benzoxazoles and benzothiazoles}

Farahi et al. $^{41}$ have developed a green protocol for the synthesis of benzoxazole and benzothiazole derivatives through the reactions of orthoesters with ortho-aminophenols or orthoaminothiophenols respectively in high yields (Scheme 12). All these reaction were carried out in the presence of tungstate sulfuric acid (TSA) under solvent free condition at $80-90{ }^{\circ} \mathrm{C}$. In a comparative study, authors employed various catalysts such as $\mathrm{ZnCl}_{2}, \mathrm{MgBr}_{2}$ and $\mathrm{H}_{2} \mathrm{SO}_{4}$ in this reaction, but they did not give good results. In addition, solvent free conditions give better results.

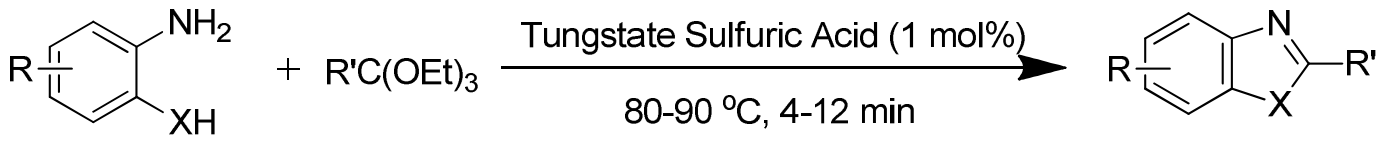

$$
\begin{aligned}
& \text { (1 mmol) } \\
& \text { (1.1 mmol) } \\
& \begin{array}{l}
\mathrm{R}=\mathrm{H}, \mathrm{Me}, \mathrm{Cl}, \mathrm{NO}_{2} \\
\mathrm{R}^{\prime}=\mathrm{H}, \mathrm{Me}, \mathrm{Et}
\end{array} \\
& X=S, O
\end{aligned}
$$

Scheme 12. Synthesis of benzoxazoles and benzothiazoles catalyzed by TSA. 


\subsection{Biginelli condensation reaction}

Karami et al. have ${ }^{42}$ discovered an efficient protocol for the synthesis of 3,4-dihydropyrimidine$2-(1 H)$ thione derivatives via condensation of $\beta$-dicarbonyls, various aldehydes and thiourea using tungstate sulfuric acid (TSA) (Scheme 13). These all transformations were performed under solvent-free conditions at $80{ }^{\circ} \mathrm{C}$. Both electrons-releasing and electron-withdrawing groups on the aryl aldehyde reacted smoothly in this method. Here, the reaction temperature affected the yield of the products.

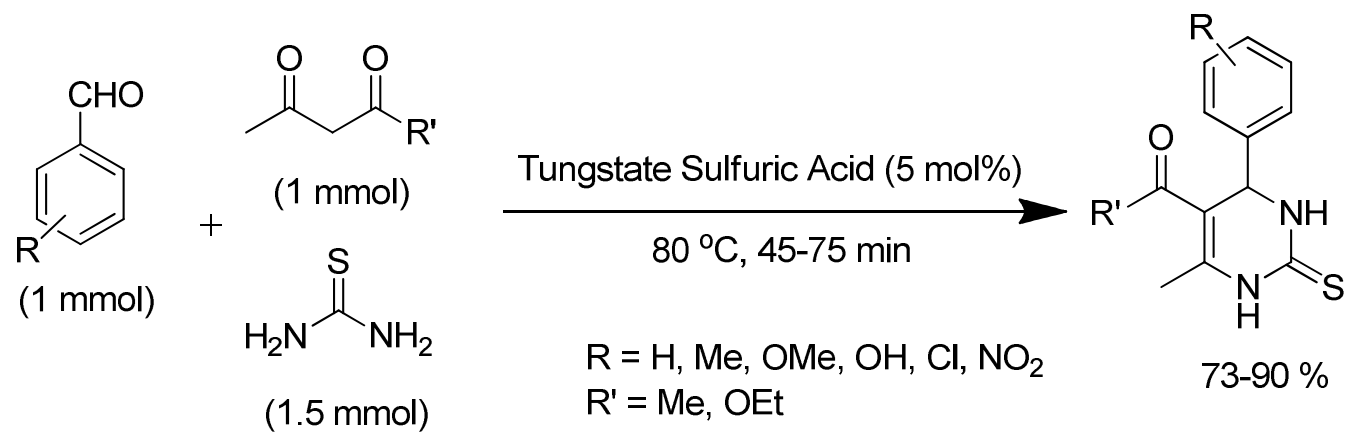

Scheme 13. Biginelli condensation reaction catalyzed by TSA.

\subsection{Rapid deoximation of oximes}

Karami et al. $^{43}$ have reported deoximation of a variety of oximes oxidized to their parent carbonyl compounds in excellent yield under the mild conditions using heterogeneous wet $\mathrm{TSA} / \mathrm{KMnO}_{4}$ in dichloromethane (DCM) (Scheme 14). Various oximes were deoximated to their parent carbonyl compounds efficiently by this method.

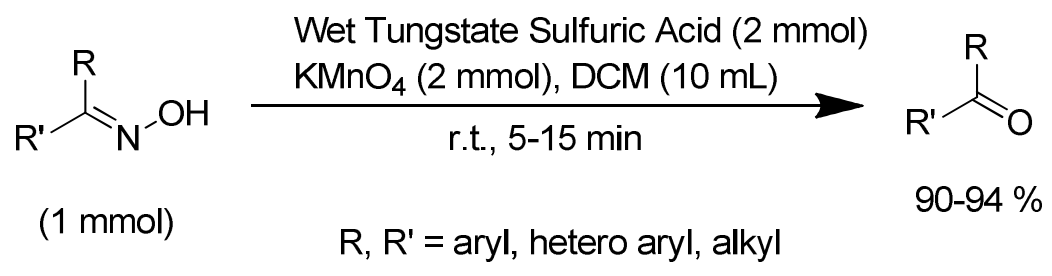

Scheme 14. Rapid deoximation of oximes catalyzed by TSA.

\subsection{Synthesis of 1,3-dithiane and 1,3-dithiolane derivatives}

Karami et al. $^{44}$ have disclosed an efficient protocol for the thioacetalization of aliphatic and aromatic carbonyl compounds using tungstate sulfuric acid (TSA) as an eco-friendly catalyst under solvent-free conditions at $80^{\circ} \mathrm{C}$ or by grinding at room temperature to afford 1,3-dithianes and 1,3-dithiolanes (Scheme 15). Here, the reaction mechanism shows that TSA is a strong, solid acid and it can activate the carbonyl group to enhance the rate of the reaction. Several aromatic and aliphatic carbonyl compounds with electron-releasing or electron-withdrawing substituents 
afforded good to excellent yields of the products. The grinding technique required less time to complete the reaction as compared to conventional heating conditions.
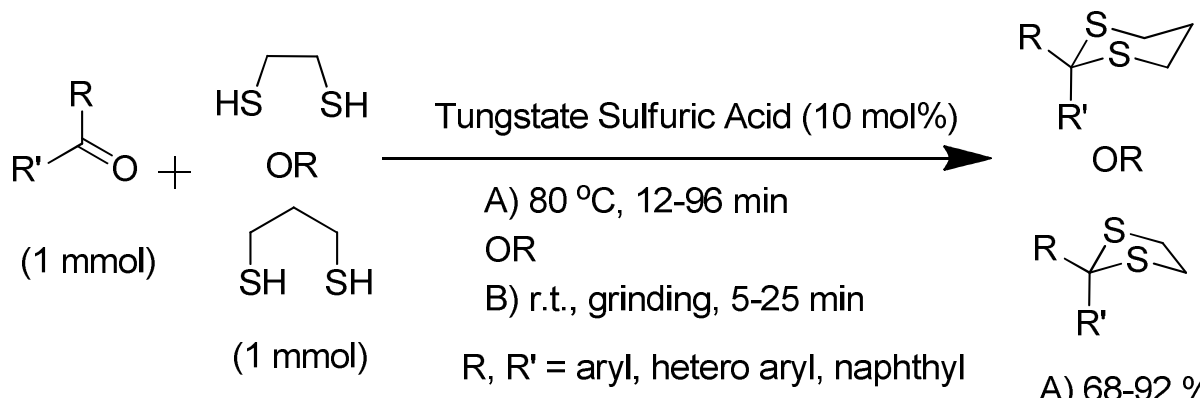
A) $68-92 \%$
B) $70-96 \%$

Scheme 15. Synthesis of 1,3-dithiane and 1,3-dithiolane derivatives catalyzed by TSA.

\subsection{Oxidation of thiols to disulfides and oxidative demasking of 1,3-dithianes}

Karami et al. ${ }^{45}$ have developed a combination of tungstate sulfuric acid (TSA) and $\mathrm{NaNO}_{2}$ as an oxidant for the transformation of thiols to disulfides in dichloromethane (DCM) at room temperature in high yields (Scheme 16a). The selective oxidative deprotection of 1,3-dithianes to their corresponding carbonyl compounds using tungstate sulfuric acid (TSA) in combination with $\mathrm{KMnO}_{4}$ in dichloromethane (DCM) under reflux condition has also been investigated by the authors (Scheme 16b).

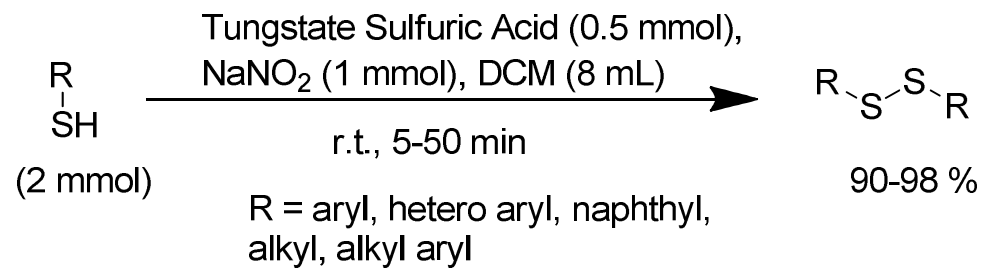

Scheme 16a. Oxidation of thiols to disulfides catalyzed by TSA.

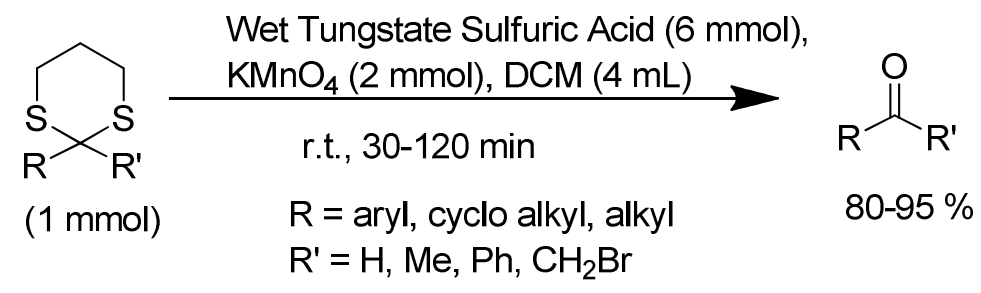

Scheme 16b. Oxidative demasking of 1,3-dithianes catalyzed by TSA. 


\subsection{N-Nitrosation of secondary amines}

Karami et al. ${ }^{46}$ have described an efficient and fast method for $\mathrm{N}$-nitrosation of versus $C$ nitrosation or $O$-nitrosation of various secondary amines using $\mathrm{TSA} / \mathrm{NaNO}_{2}$ in dichloromethane (DCM) at room temperature (Scheme 17). The mechanism proposed by the authors reveals that the reaction proceeds through the formation of $\mathrm{NO}^{+}$by the reaction of wet TSA and $\mathrm{NaNO}_{2}$, which then reacts with various secondary amines affording the corresponding nitroso products in excellent yield. In addition, mild and eco-friendly reaction conditions, easily accessible reagents and a simple work-up process are the advantages of this protocol.

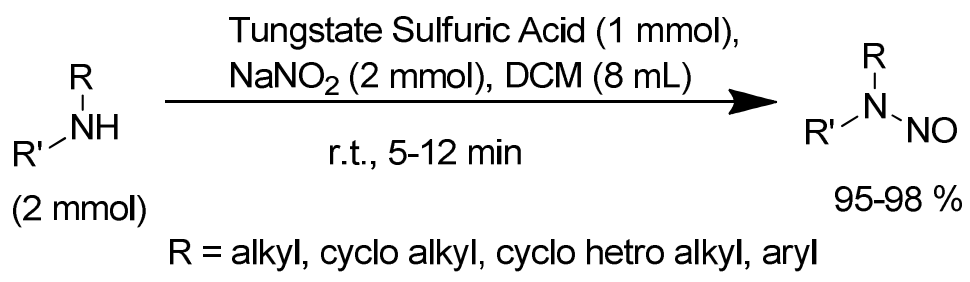

Scheme 17. N-Nitrosation of secondary amines catalyzed by TSA.

\subsection{Synthesis of benzimidazoles}

Karami et al. ${ }^{47}$ have discovered an eco-friendly and high yielding protocol for the synthesis of benzimidazoles through a condensation reaction of ortho-phenylenediamines with orthoesters by employing tungstate sulfuric acid (TSA) under solvent-free conditions at $80{ }^{\circ} \mathrm{C}$ (Scheme 18).

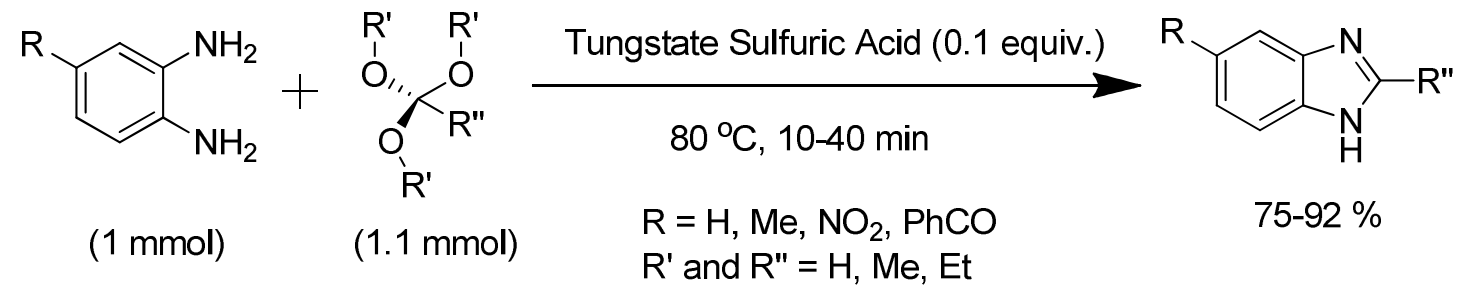

Scheme 18. Synthesis of benzimidazoles catalyzed by TSA.

\subsection{Synthesis of polycyclic aromatic phenazines and quinoxalines}

Karami and co-workers ${ }^{48}$ have been developed high yielding synthesis of quinoxalines and phenazines by the condensation of 1,2-dicarbonyl compounds and ortho-phenylenediamines in the presence of tungstate sulfuric acid (TSA) without the use of any solvent (Scheme 19). All reactions were performed at ambient temperature. Here, 5 mole $\%$ TSA was sufficient for completion of the reaction. However, by using higher amounts of catalyst, the product yield and time of the reaction did not improve. 


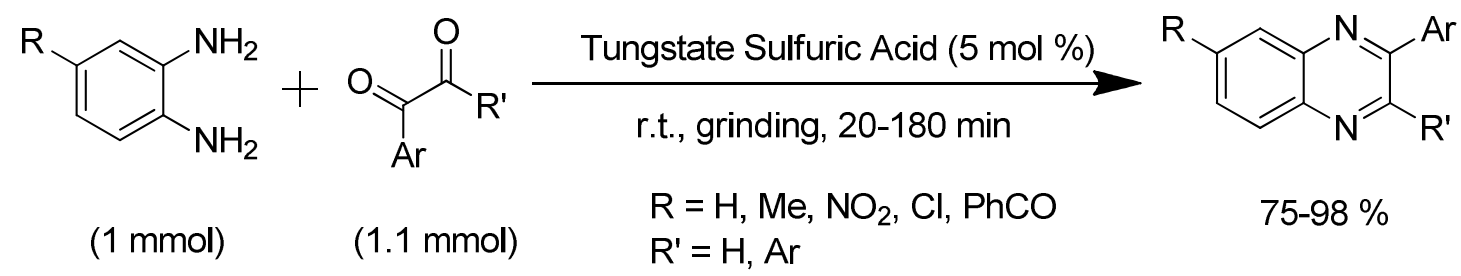

Scheme 19. Synthesis of polycyclic aromatic phenazines and quinoxalines catalyzed by TSA.

\subsection{Synthesis of calix[4]resorcinarene derivatives}

Karami and co-workers ${ }^{49}$ have discovered a facile and simple method for the preparation of novel calix[4]resorcinarene derivatives through the condensation of aryl aldehydes with resorcinol using tungstate sulfuric acid (TSA) under solvent-free conditions at $120{ }^{\circ} \mathrm{C}$ (Scheme 20). The use of excessive amounts of the catalyst does not increase the yield of the products and reaction time. This eco-friendly method has many advantages, such as high yield, lesser reaction time, use of safe and recoverable catalyst, and workup.

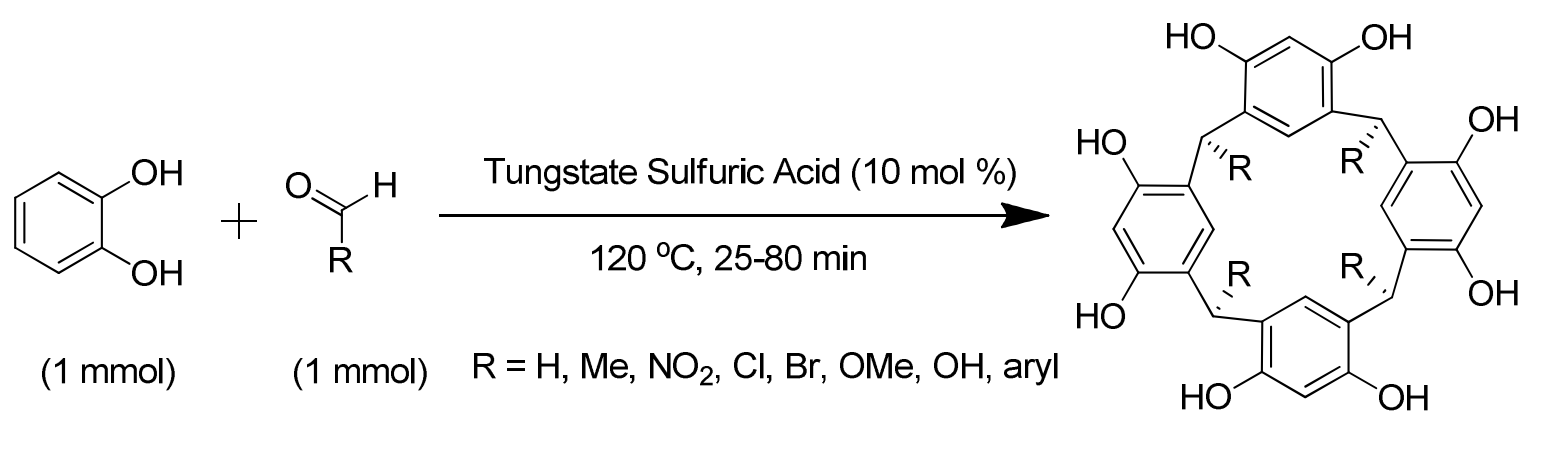

$78-95 \%$

Scheme 20. Synthesis of calicx[4]resorcinarene derivatives catalyzed by TSA.

\section{Molybdate Sulfuric Acid (MSA)}

MSA is prepared according to following method: anhydrous sodium molybdate ( $20 \mathrm{mmol}, 4.118$ g) was added to dry n-hexane $(25 \mathrm{~mL})$ in a $100 \mathrm{~mL}$ round bottom flask equipped with ice bath and overhead stirrer. Chlorosulfonic acid $(0.266 \mathrm{~mL}, 40 \mathrm{mmol})$ was then added drop wise to the flask during $30 \mathrm{~min}$ and stirred for $1.5 \mathrm{~h}$. The reaction mixture was gradually poured into $25 \mathrm{~mL}$ of chilled distilled water with agitation. The molybdate sulfuric acid was separated as a bluish solid by filtration, washed with cold distilled water five times until the negative test for chloride ion for filtrate, and dried at $120{ }^{\circ} \mathrm{C}$ for $5 \mathrm{~h} .{ }^{52} \mathrm{MSA}$ is environmentally benign, easy to handle and is stable in reaction media. It can be stored for a longer time without loss of activity. Also it is 
easily recovered after completion of the reaction and it can be reused several times without loss of activity.

\subsection{Synthesis of $2,3,4,5$-tetrasubstituted pyrroles}

Tamaddon et al. ${ }^{50}$ have discovered the solvent-free preparation of 2,3,4,5-tetrasubstituted pyrroles through the $[2+2+1]$ strategy via condensation of 1,3-dicarbonyls, benzoin derivatives and ammonium acetate in the presence of catalytic amounts of molybdate sulfuric acid (MSA), which afforded high yields of the products (Scheme 21). Solvents like ethanol, water, dichloromethane and acetonitrile were examined by the authors. However, ethanol gave better results as compared to the other solvents. In a comparative study, various catalysts such as $\mathrm{ZrOCl}_{2}, \mathrm{ZnCl}_{2}, \mathrm{MgBr}_{2}, \mathrm{CuCl}_{2}, \mathrm{H}_{2} \mathrm{SO}_{4}, \mathrm{HCl}, \mathrm{CH}_{3} \mathrm{COOH}$ and $\mathrm{MSA}$ were employed in this reaction, but MSA proved to be the best performing catalyst. Here, the mechanism shows that the 1,3-dicarbonyl compound reacts initially with $\mathrm{NH}_{4} \mathrm{OAc}$ to form an imine intermediate, then it condenses with activated benzoin by MSA to produce a cyclic intermediate, which could be dehydrated to produce the corresponding tetra substituted pyrroles.

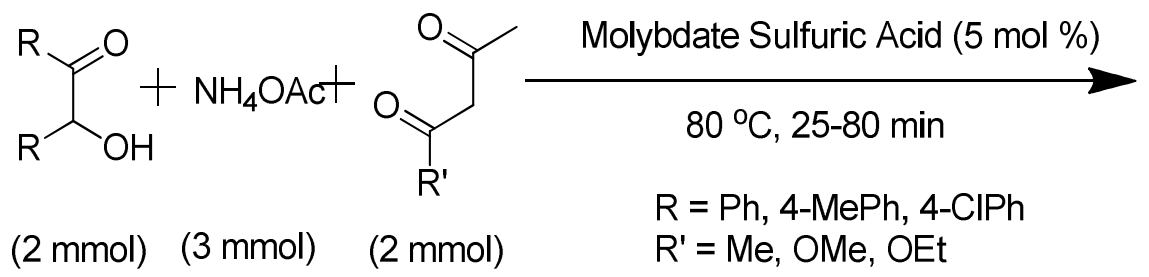

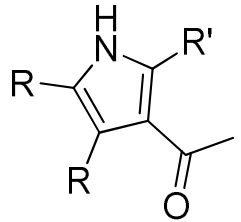

$87-96 \%$

Scheme 21. Synthesis of 2,3,4,5-tetrasubstituted pyrroles catalyzed by MSA.

\subsection{Synthesis of gem-bisamide}

Tamaddon et al. ${ }^{51}$ have developed another protocol for the high yielding synthesis of gembisamides and bisurides through condensation of two moles of amides, nitriles, carbamates or urea with aldehydes in the presence of molybdate sulfuric acid (MSA) and silica sulfuric acid (SSA) as catalysts in ethyl acetate at $80-90{ }^{\circ} \mathrm{C}$ (Scheme 22). Best results were obtained by using MSA and SSA in terms of yield, selectivity and reaction time as compared to commercial sulfuric acid. Both electrons-donating and electron-withdrawing groups on aldehydes, amides, urea and carbamates gave the $N, N$-arylidene and alkylidene bisamides in high yields. The mechanism of this transformation suggests that initially MSA or SSA activates the carbonyl group of aldehyde for reaction with amide to form a hemiamidal intermediate. Subsequently, this hemiamidal dehydrates to an acyliminium intermediate and it condenses with another molecule of amide to form the gem-bisamide. 


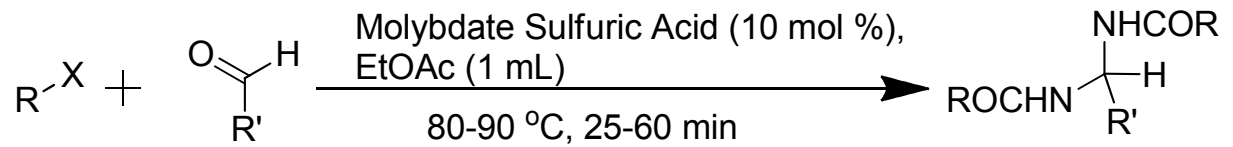

$$
\begin{aligned}
& \text { (4 mmol) (2 mmol) } \quad \mathrm{R}=\text { alkyl, aryl, } \mathrm{NH}_{2}, \mathrm{OMe} \quad \text { 83-91\% } \\
& \mathrm{R}^{\prime}=\text { alkyl, aryl } \\
& \mathrm{X}=\mathrm{CONH}_{2}, \mathrm{CN}
\end{aligned}
$$

Scheme 22. Synthesis of gem-bisamide catalyzed by MSA.

\subsection{Synthesis of disulfides}

Montazerozohori and co-workers ${ }^{52}$ have reported a mild method for the synthesis of symmetric disulfides from a variety of thiols using sodium nitrite and wet molybdate sulfuric acid (MSA) in dichloromethane or methanol at room temperature (Scheme 23).

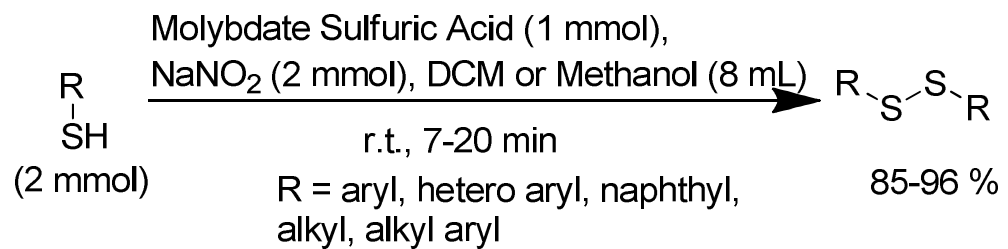

Scheme 23. Synthesis of disulfides catalyzed by MSA.

\subsection{Synthesis of quinoxaline and phenazine derivatives}

Karami et al. ${ }^{53}$ have discovered an efficient synthesis of quinoxaline and phenazine derivatives by the reaction of 1,2-diketones and ortho-pheneylenediamines using a catalytic amount of molybdate sulfuric acid (MSA) in ethanol as solvent at room temperature (Scheme 24a-b). This protocol is considered to have a wide synthetic utility because of the wide variety of 1,2diketones and ortho-pheneylenediamines that were employed in this reaction.

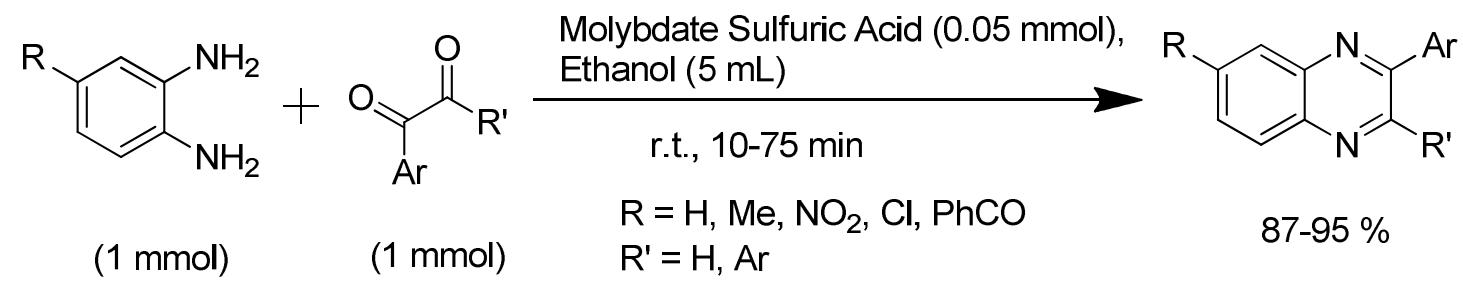

Scheme 24a. Synthesis of quinoxaline derivatives catalyzed by MSA. 


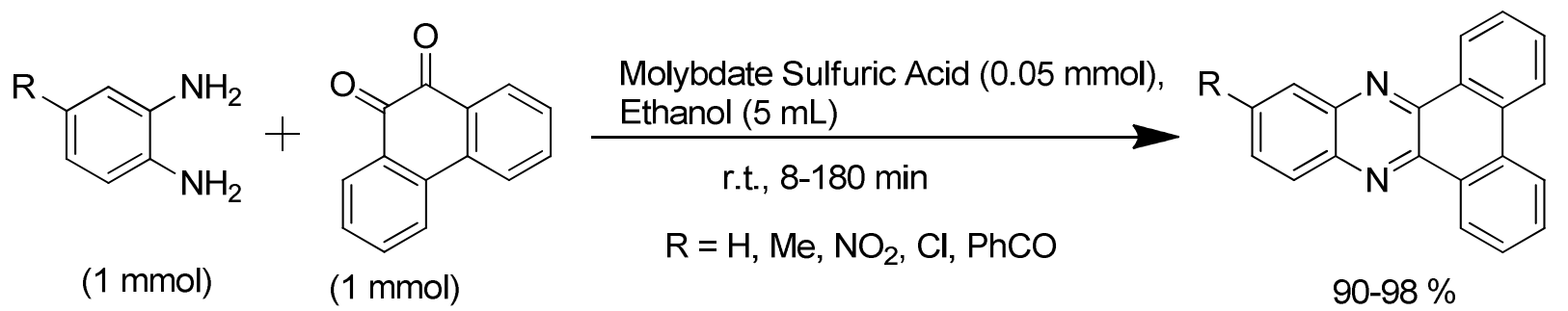

Scheme 24b. Synthesis of phenazine derivatives catalyzed by MSA.

\subsection{Synthesis of $\mathrm{N}$-nitroso compounds}

Montazerozohori et al. ${ }^{54}$ have described an environmental friendly procedure for the synthesis of $\mathrm{N}$-nitroso compounds in excellent yield from a variety of secondary amines employing wet molybdate sulfuric acid (MSA) and sodium nitrite $\left(\mathrm{NaNO}_{2}\right)$ in dichloromethane (DCM) at room temperature (Scheme 25). Furthermore, N-nitrosation was observed selectively instead of $C$ - or O-nitrosation.

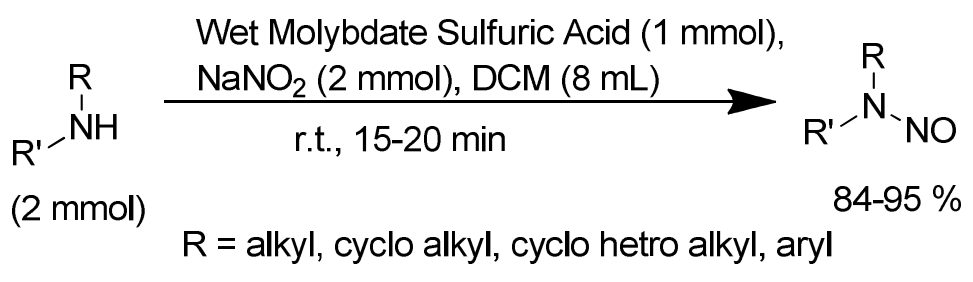

Scheme 25. Synthesis of N-nitroso compounds catalyzed by MSA.

\section{Xanthan Sulfuric Acid (XSA)}

Xanthan is the most abundant bacterial exo-polysaccharide in the world and is produced through fermentation. It has been widely studied in the last few years, as it is a biodegradable material and a renewable resource. In addition, it is very stable under a wide range of temperatures and $\mathrm{pH}$ conditions. The xanthan sulfuric acid (XSA) catalyst was prepared by following method: To a magnetically stirred mixture of $5.0 \mathrm{~g}$ xanthan in $20 \mathrm{~mL} \mathrm{CHCl}_{3}$, chlorosulfonic acid $(9 \mathrm{mmol}$, $1.0 \mathrm{~g}$ ) was added dropwise at $0{ }^{\circ} \mathrm{C}$ during $2 \mathrm{~h}$. After addition was complete, the mixture was stirred for $2 \mathrm{~h}$ until $\mathrm{HCl}$ was removed from the reaction vessel. The mixture was then filtered and washed with $30 \mathrm{~mL}$ methanol or acetonitrile and dried at room temperature to afford $5.26 \mathrm{~g}$ xanthan sulfuric acid as white powder. ${ }^{55}$

Xanthan sulfuric acid is a heterogeneous catalyst and it is recovered and reused many times without loss of activity. 


\subsection{Synthesis of bis(indolyl)methane derivatives}

Siddiqui and co-workers ${ }^{56}$ have developed a solvent free procedure for the synthesis of bis(indolyl)methanes by using indole and aromatic aldehydes in the presence of xanthan sulfuric acid (XSA) by grinding at room temperature to afford the products in high yield (Scheme 26). Various catalysts such as zinc acetate, $\mathrm{NiCl}_{2}, \mathrm{AlCl}_{3}$, benzenesulfonic acid, sulfuric acid, sulfamic acid, L-proline and $\mathrm{Zn}$ (L-proline) $)_{2}$ were employed in this reaction in a comparative study; however, they did not give good results. In addition, different solvents like methanol, ethanol, acetonitrile, 1,2-dichloroethane, acetic acid and iso-propanol were examined by the authors for optimization of the yield of the products and reaction time. It was found that the solvent free condition proved to be the best for this reaction.<smiles>IC1(I)C=Cc2ccccc2N1</smiles>

$(2 \mathrm{mmol})$<smiles>[R]C=O</smiles>

$(1 \mathrm{mmol})$

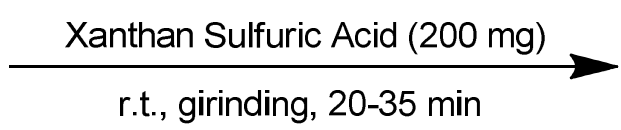

$\mathrm{R}=$ aryl, hetero aryl

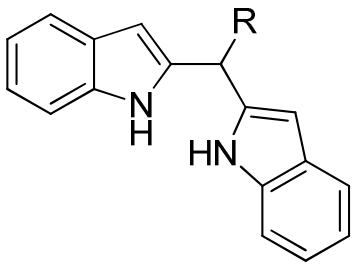

84-92\%

Scheme 26. Synthesis of bis(indolyl)methane derivatives catalyzed by XSA.

\subsection{Synthesis of $N$-substituted pyrroles}

Rahmatpour $^{57}$ has disclosed a solvent-free protocol for the synthesis of various of $N$-substituted pyrroles by the reaction of 2,5-hexanedione with various amines or diamines in the presence catalytic amount of xanthan sulfuric acid (XSA) at room temperature (Scheme 27). In this protocol, all the products were obtained in excellent yields. The use of a non-hazardous, inexpensive, readily available and reusable bio-supported proton source catalyst makes this protocol green and environmentally friendly. This transformation was carried out by employing various solvents such as dichloromethane, chloroform, carbon tetrachloride and acetonitrile, but solvent free conditions were found to be the most favorable for this transformation in terms of the yield of the products. In addition, an excessive amount of catalyst did not increase the yield of the products in this protocol.

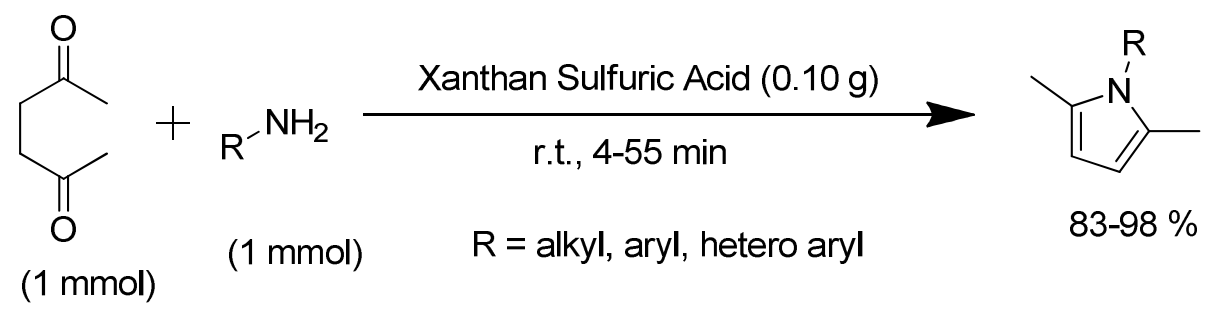

Scheme 27. Synthesis of N-substituted pyrroles catalyzed by XSA. 


\subsection{Pechmann condensation reaction}

Kuarm et al. ${ }^{58}$ have disclosed a solvent-free preparation of substituted coumarins via Pechmann condensation of various phenols and ethyl acetoacetate derivatives using catalytic amounts of xanthan sulfuric acid (XSA) at room temperature (Scheme 28). The lower yield of the product was obtained, when lower amounts of catalyst were used. In the absence of catalyst the yield of the product was very poor. However, best results were obtained when 10 mole $\%$ of XSA was used as a catalyst. Various catalysts such as silica sulfuric acid, methane sulfonic acid and sulfuric acid in acetic acid were used in this reaction, but they were not as efficient as XSA.

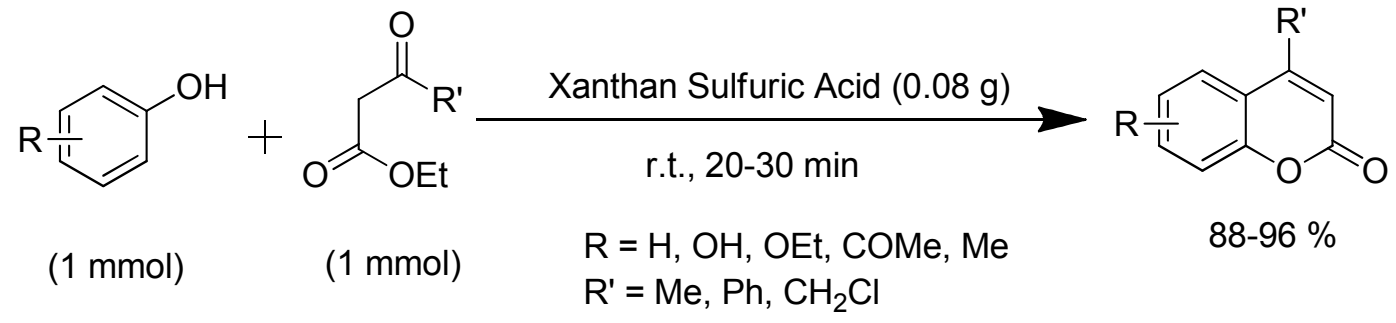

Scheme 28. Pechmann condensation reaction catalyzed by XSA.

\subsection{Synthesis of 4,4 '-(arylmethylene)bis( $1 \mathrm{H}$-pyrazol-5-ols)}

Kuarm et al. ${ }^{59}$ have reported an efficient protocol for the synthesis of 4,4'(arylmethylene)bis(1H-pyrazol-5-ols) via the condensation of 1-phenyl-3-methylpyrazol-5-one and various aldehydes by employing catalytic amounts of xanthan sulfuric acid (XSA) in ethanol under reflux conditions (Scheme 29).

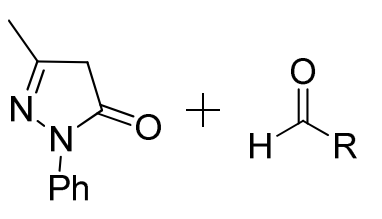

(2 mmol)

$(1 \mathrm{mmol})$

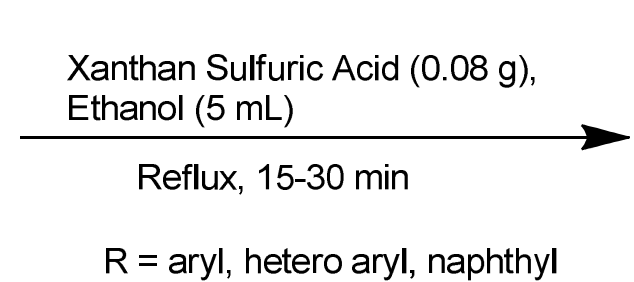

$\mathrm{R}=$ aryl, hetero aryl, naphthyl

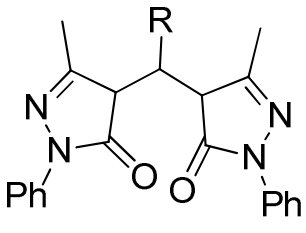

$76-95 \%$

Scheme 29. Synthesis of 4,4'-(arylmethylene)bis(1H-pyrazol-5-ols) catalyzed by XSA.

\subsection{Synthesis of 14-Aryl-14H-dibenzo[a,i]xanthene-8,13-dione}

Kuarm et al. ${ }^{60}$ have discovered an efficient protocol for the high yielding synthesis of 14-aryl$14 H$-dibenzo[ $a, i]$ xanthene-8,13-diones through the condensation of 2-hydroxynaphthalene-1,4dione, 2-naphthol and various aromatic aldehydes in the presence of xanthan sulfuric acid (XSA) as a recyclable catalyst in ethanol at $50{ }^{\circ} \mathrm{C}$ (Scheme 30$)$. 


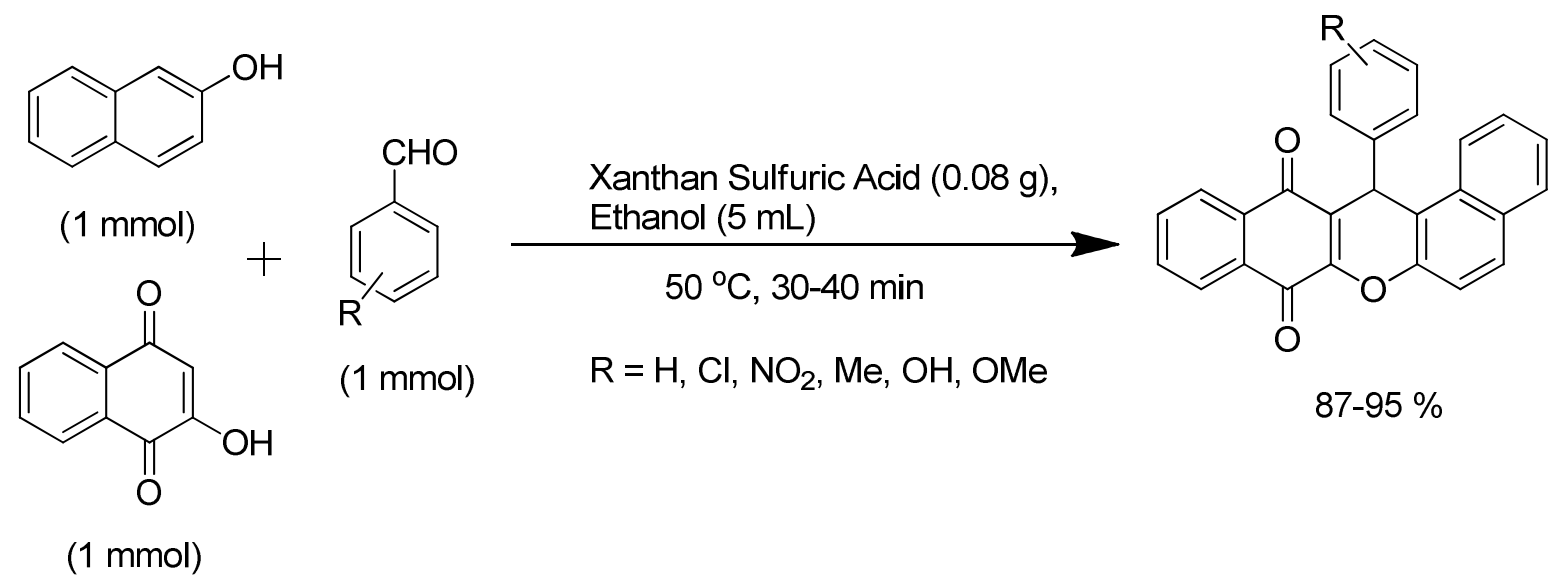

Scheme 30. Synthesis of 14-Aryl-14H-dibenzo[a,i]xanthene-8,13-dione catalyzed by XSA.

\subsection{Synthesis of $\alpha$-amino phosphonates}

Sun et al. ${ }^{61}$ have described an solvent-free procedure for the development of $\alpha$-amino phosphonates via condensation of various aldehydes, diethyl phosphate and amine by using catalytic amount of xanthan sulfuric acid at the $60{ }^{\circ} \mathrm{C}$ (Scheme 31). The effects of catalyst loading and temperature of the reaction on the yield of the products and rate of the reaction were also investigated by the authors. A wide range of $\alpha$-amino phosphonates have been obtained by this protocol, making it have a potentially a wide synthetic utility.

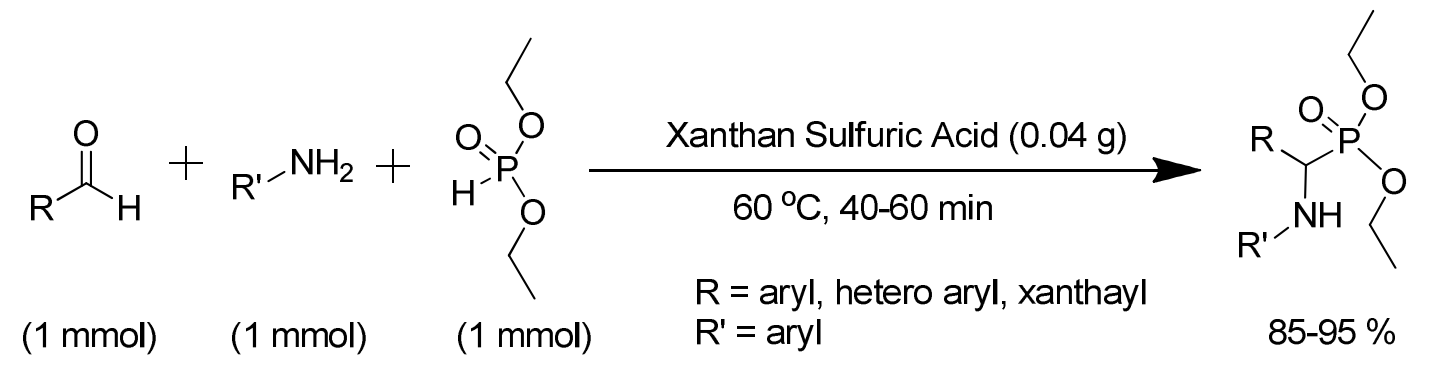

Scheme 31. Synthesis of $\alpha$-amino phosphonates catalyzed by XSA.

\subsection{Biginelli condensation reaction}

Kuarm et al. ${ }^{62}$ have disclosed a solvent-free method for the synthesis of 3,4-dihydropyrimidin$2(1 H)$-ones/thiones via a one-pot, three-component Biginelli condensation reaction of aldehydes, amines, and urea/thiourea at the $40{ }^{\circ} \mathrm{C}$ (Scheme 32). Various solvents such as methanol, acetonitrile, dichloromethane, toluene and ethanol were employed in a comparative study. However, solvent free conditions were found to be preferable for this transformation in terms of the yield of the products. 


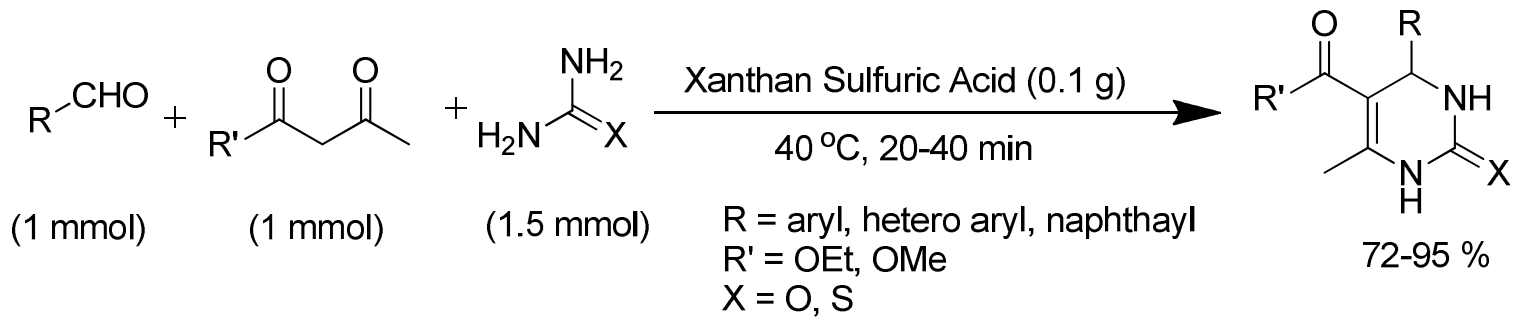

Scheme 32. Biginelli condensation reaction catalyzed by XSA.

\subsection{Synthesis of $\alpha$-amino nitriles}

Shaabani et al. ${ }^{63}$ have discovered the condensation reaction of aldehydes or ketones, amines and trimethylsilylcyanide in the presence of a catalytic amount of xanthan sulfuric acid (XSA) at room temperature, which afforded $\alpha$-amino nitriles in excellent yields (Scheme 33). The results showed that the efficiency and the yield of the products in acetonitrile were found to be higher compared with other solvents such as water, ethanol, methanol, dichloromethane and toluene or under solvent-free conditions.

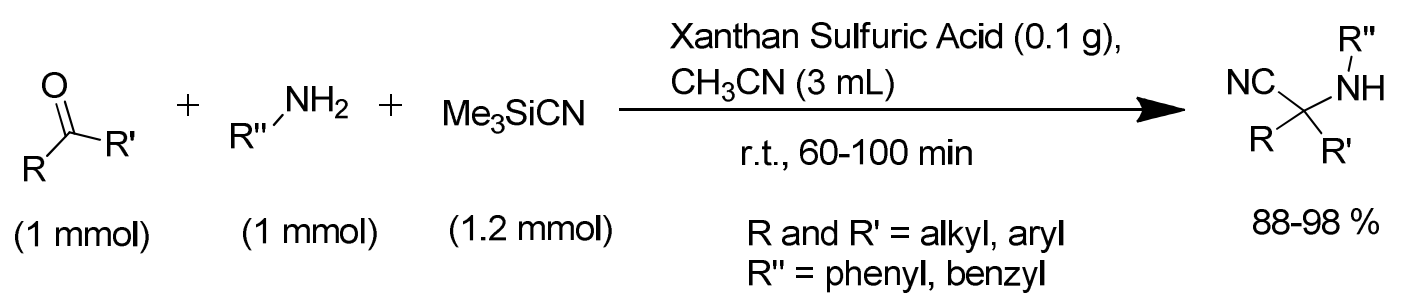

Scheme 33. Synthesis of $\alpha$-amino nitriles catalyzed by XSA.

\section{Conclusions}

This review summarizes the development of green organic transformations catalyzed by sulfuric acid based solid, heterogeneous catalysts. In recent years, alumina sulfuric acid (ASA), tungstate sulfuric acid (TSA), molybdate sulfuric acid (MSA) and xanthan sulfuric acid (XSA) have been explored for improving selectivity, purity and high yields of organic compounds. Particularly, ASA and TSA are widely used in efficient synthesis methodologies of many organic transformations. Moreover, recoverability and reusability of these four catalysts make all process environmentally friendly, cost-effectiveness and green. It should be noted that though great progress has been achieved in this field over the last few years, this research area has still further possibilities for growth and, no doubt, we will see an increasing number of new and novel procedures for the synthesis of various organic compounds catalyzed by solid heterogeneous catalysts. 


\section{Acknowledgements}

The authors are thankful to the Department of Chemistry, Gujarat University, Ahmedabad, for providing the necessary facilities. UGC-Info net \& INFLIBNET Gujarat University are acknowledged for providing the e-source facilities. R.H.V. is thankful to UGC-BSR (F.774/2007 (BSR)) for financial assistance.

\section{References}

1. Anastas, P. T.; Kirchhoff, M. M. Acc. Chem. Res. 2002, 35, 686. http://dx.doi.org/10.1021/ar010065m

2. Jiang, H. Y.; Yang, C. F.; Li, C.; Fu, H. Y.; Chen, H.; Li, R. X.; Li, X. Angew. Chem. Int. Ed. 2008, 47, 9240. http://dx.doi.org/10.1002/anie.200801809

3. Jiang, H. Y.; Sun, B.; Zheng, X. X.; Chen, H. Appl. Catal., A: Gen. 2012, 421, 86. http://dx.doi.org/10.1016/j.apcata.2012.02.002

4. Zhou, J.; Wan, J.; Ma, X.; Wang, W. Org. Biomol. Chem. 2012, 10, 4179. http://dx.doi.org/10.1039/c2ob25106j

5. Herrmann, W. A.; Kohlpaintner, C. W. Angew. Chem. Int. Ed. 1993, 32, 1524. http://dx.doi.org/10.1002/anie.199315241

6. Baleizao, C.; Garcia, H. Chem. Rev. 2006, 106, 3987. http://dx.doi.org/10.1021/cr050973n

7. Sanz, R.; Miguel, D.; Martínez, A.; Álvarez-Gutiérrez, J. M.; Rodríguez, F. Org. Lett. 2007, 9, 727-730. http://dx.doi.org/10.1021/o10631298

8. Farina, V. Adv. Synth. Catal. 2004, 346, 1553-1582. http://dx.doi.org/10.1002/adsc.200404178

9. Corma, A.; Garcia, H. Chem. Rev. 2003, 103, 4307. http://dx.doi.org/10.1021/cr030680z

10. Hasaninejad, A.; Zare, A.; Shekouhy, M.; Ameri-Rad, J. Green Chem. 2011, 13, 958. http://dx.doi.org/10.1039/c0gc00953a

11. Zhang, Z.; Du, B.; Zhang, L. J.; Da, Y. X.; Quan, Z. J.; Yang, L. J.; Wang, X. C. RSC Adv. 2013, 3, 9201.

12. Hasaninejed, A.; Kazerooni, M. R.; Zare, A. Catal. Today 2012, 196, 148. http://dx.doi.org/10.1016/j.cattod.2012.05.026

13. Clark, J. H. Acc. Chem. Res. 2002, 35, 791. http://dx.doi.org/10.1021/ar010072a

14. Shanmugam, S.; Viswanathan, B.; Varadarajan, T. J. Mol. Catal. A: Chem. 2004, 223, 143. http://dx.doi.org/10.1016/j.molcata.2004.02.030 
15. Zolfigol, M. A. Tetrahedron 2001, 57, 9509. http://dx.doi.org/10.1016/S0040-4020(01)00960-7

16. Salehi, P.; Dabiri, M.; Zolfigol, M. A.; Bodaghi Fard, M. A. Tetrahedron Lett. 2003, 44, 2889.

http://dx.doi.org/10.1016/S0040-4039(03)00436-2

17. Bigi, F.; Chesini, L.; Maggi, R.; Sartori, G. J. Org. Chem. 1999, 64, 1033. http://dx.doi.org/10.1021/jo981794r

18. Chaudhari, P. S.; Salim, S. D.; Sawant, R. V.; Akamanchi, K. G. Green Chem. 2010, 12, 1707. http://dx.doi.org/10.1039/c0gc00053a

19. Climent, M. J.; Corma, A.; Iborra, S. Green Chem. 2011, 13, 520. http://dx.doi.org/10.1039/c0gc00639d

20. Salehi, P.; Ali Zolfigol, M.; Shirini, F.; Baghbanzadeh, M. Curr. Org. Chem. 2006, 10, 2171. http://dx.doi.org/10.2174/138527206778742650

21. Reddy, B. M.; Patil, M. K. Curr. Org. Chem. 2008, 12, 118. http://dx.doi.org/10.2174/138527208783330019

22. Sartori, G.; Ballini, R.; Bigi, F.; Bosica, G.; Maggi, R.; Righi, P. Chem. Rev. 2004, 104, 199. http://dx.doi.org/10.1021/cr0200769

23. Hasaninejad, A.; Shekouhy, M.; Golzar, N.; Zare, A.; Doroodmand, M. M. Appl. Catal., A: Gen. 2011, 402, 11.

http://dx.doi.org/10.1016/j.apcata.2011.04.012

24. Sharghi, H.; Eskandari, R. J. Chem. Res. 2005, $2005,488$.

25. Shaterian, H. R.; Hosseinian, A.; Yarahmadi, H.; Ghashang, M. Lett. Org. Chem. 2008, 5, 290.

http://dx.doi.org/10.2174/157017808784049524

26. Hosseini-Sarvari, M.; Sharghi, H. J. Chem. Res. 2006, 2006, 205.

27. Pramanik, A.; Roy, R.; Khan, S.; Ghatak, A.; Bhar, S. Tetrahedron Lett. 2014, 55, 1771. http://dx.doi.org/10.1016/j.tetlet.2014.01.125

28. M. Hosseini-Sarvari; Tavakolian, M.; Ashenagar, S., Iran. J. Sci. Technol. A. 2010, 34, 215.

29. Teimouri, A.; Salavati, H.; Chermahini, A. N. Acta Chim. Slov. 2014, 61, 51.

30. Shaterian, H. R.; Hosseinian, A.; Ghashang, M. Synth. Commun. 2008, 38, 4097. http://dx.doi.org/10.1080/00397910802272022

31. Shaterian, H. R.; Khorami, F.; Amirzadeh, A.; Ghashang, M.; Hosseinian, A. Phosphorus, Sulfur Silicon Relat. Elem. 2008, 183, 2584. http://dx.doi.org/10.1080/10426500801967955

32. Shaterian, H. R.; Hosseinian, A.; Ghashang, M., Phosphorus, Sulfur Silicon Relat. Elem. 2008, 184, 197. http://dx.doi.org/10.1080/10426500802083182

33. Besoluk, S.; Kucukislamoglu, M.; Nebioglu, M.; Zengin, M.; Arslan, M. J. Iran. Chem. Soc. 2008, 5,62 . 
34. Amoozadeh, A.; Ahmadzadeh, M.; Kolvari, E. J. Chem. 2013, 2013, 1. http://dx.doi.org/10.1155/2013/767825

35. Pramanik, A.; Bhar, S. Catal. Commun. 2012, 20, 17. http://dx.doi.org/10.1016/j.catcom.2011.12.036

36. Arslan, M.; Faydali, C.; Zengin, M.; Kucukislamoglu, M.; Demirhan, H. Turk. J. Chem. 2009, 33, 769.

37. Teimouri, A.; Chermahini, A. N.; Ghorbanian, L. World Acad. Sci. Eng. Technol. 2013, 7, 1343.

38. Karami, B.; Eskandari, K.; Azizi, M. Lett. Org. Chem. 2013, 10, 722. http://dx.doi.org/10.2174/15701786113109990044

39. Karami, B.; Montazerozohori, M.; Habibi, M. H.; Zolfigol, M. A. Heterocycl. Commun. 2005, 11, 513. http://dx.doi.org/10.1515/HC.2005.11.6.513

40. Kamaei, V.; Karami, B.; Khodabakhshi, S. Polycyclic Aromat. Compd. 2014, 34, 1. http://dx.doi.org/10.1080/10406638.2013.837396

41. Farahi, M.; Karami, B.; Azari, M. C. R. Chim. 2013, 16, 1029. http://dx.doi.org/10.1016/j.crci.2013.03.009

42. Karami, B.; Haghighijou, Z.; Farahi, M.; Khodabakhshi, S. Phosphorus, Sulfur Silicon Relat. Elem. 2012, 187, 754. http://dx.doi.org/10.1080/10426507.2011.616562

43. Karami, B.; Montazerozohori, M. Molecules 2006, 11, 720. http://dx.doi.org/10.3390/11090720

44. Karami, B.; Taei, M.; Khodabakhshi, S.; Jamshidi, M. J. Sulfur Chem. 2012, 33, 65. http://dx.doi.org/10.1080/17415993.2011.629659

45. Karami, B.; Montazerozohori, M.; Habibi, M. H. Phosphorus, Sulfur Silicon Relat. Elem. 2006, 181, 2825. http://dx.doi.org/10.1080/10426500600864965

46. Karami, B.; Montazerozohori, M.; Habibi, M. H. Bull. Korean Chem. Soc. 2005, 26, 1125. http://dx.doi.org/10.5012/bkcs.2005.26.7.1125

47. Karami, B.; Khodabakhshi, S.; Haghighijou, Z. Chem. Pap. 2012, 66, 684. http://dx.doi.org/10.2478/s11696-012-0152-4

48. Karami, B.; Khodabakhshib, S.; Nikroozb, M. J. Chin. Chem. Soc. 2011, 58, 1. http://dx.doi.org/10.1002/jccs.201190067

49. Karami, B.; Khodabakhshi, S.; Safikhani, N.; Arami, A. Bull. Korean Chem. Soc. 2012, 33, 123. http://dx.doi.org/10.5012/bkcs.2012.33.1.123

50. Tamaddon, F.; Farahi, M.; Karami, B. J. Mol. Catal. A: Chem. 2012, 356, 85. http://dx.doi.org/10.1016/j.molcata.2012.01.003

51. Tamaddon, F.; Kargar-Shooroki, H.; Jafari, A. A., J. Mol. Catal. A: Chem. 2013, 368-369, 66. 
http://dx.doi.org/10.1016/j.molcata.2012.12.002

52. Montazerozohori, M.; Karami, B.; Azizi, M. Arkivoc 2007, 1, 99. http://dx.doi.org/10.3998/ark.5550190.0008.111

53. Karami, B. S.; Khodabakhshi, S.; Nikrooz, M. Polycyclic Aromat. Compd. 2011, 31, 97. http://dx.doi.org/10.1080/10406638.2011.572577

54. Montazerozohori, M.; Karami, B. Helv. Chim. Acta. 2006, 89, 2922. http://dx.doi.org/10.1002/hlca.20069026

55. S. Kuarm, B.; V. Madhav, J.; Rajitha, B. Lett. Org. Chem. 2011, 8, 549.

56. Siddiqui, Z. N.; Tarannum, S. C. R. Chim. 2013, 16, 829. http://dx.doi.org/10.1016/j.crci.2013.04.013

57. Rahmatpour, A. Monatsh. Chem. 2011, 143, 491. http://dx.doi.org/10.1007/s00706-011-0604-5

58. Kuarm, B. S.; Madhav, J. V.; Rajitha, B. Synth. Commun. 2012, 42, 1770. http://dx.doi.org/10.1080/00397911.2010.543964

59. Kuarm, B. S.; Rajitha, B. Synth. Commun. 2012, 42, 2382. http://dx.doi.org/10.1080/00397911.2011.557516

60. Suresh Kuarm, B.; Crooksb, P. A.; Rajitha, B. Adv. Appl. Sci. Res. 2012, 3, 1.

61. Sun, G. Y.; Hou, J. T.; Dou, J. J.; Lu, J.; Hou, Y. J.; Xue, T.; Zhang, Z. H. J. Chin. Chem. Soc. 2010, 57, 1315. http://dx.doi.org/10.1002/cjoc.20030211016

62. Kuarm, B. S.; Madhav, J. V.; Laxmi, S. V.; Rajitha, B. Synth. Commun. 2012, 42, 1211. http://dx.doi.org/10.1080/00397911.2010.538483

63. Shaabani, A.; Maleki, A.; Soudi, M. R.; Mofakham, H. Catal. Commun. 2009, 10, 945. http://dx.doi.org/10.1016/j.catcom.2008.12.035

\section{Authors' Biographies}

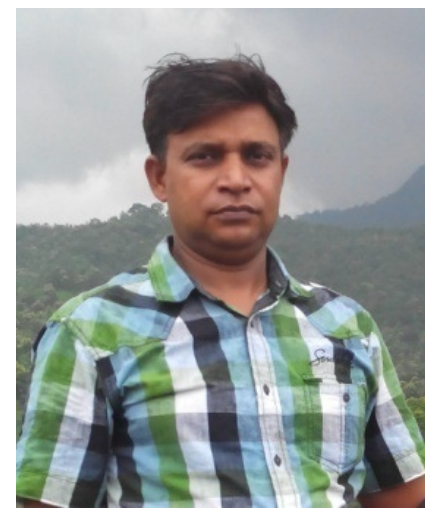

Dr. Hitesh D Patel received his Ph.D in Organic Chemistry from the South Gujarat University, Surat, Gujarat, India in 2005 under the supervision of Dr. B. D. Mistry of B. K. M. Science 
College, Valsad, Gujarat, India. He worked on the synthesis of biologically active heterocyclic compounds, their characterization by various analytical techniques and their testing for activities. He joined as a lecturer at St. Xavier's College, Ahmedabad, Gujarat, India and also had been associated with Xavier Research Foundation, Ahmedabad, India, during the period of 1998 to 2005. Since then he has joined as an Associate Professor at Department of Chemistry, Gujarat University, Ahmedabad, Gujarat, India. At present the fields of his research areas are synthetic organic chemistry via green chemistry, biological screening of synthesized compounds, the computational study of active organic molecules, the study of organic fluorescence giving compounds on infectious microorganisms, and also scale up of industrially important compounds.

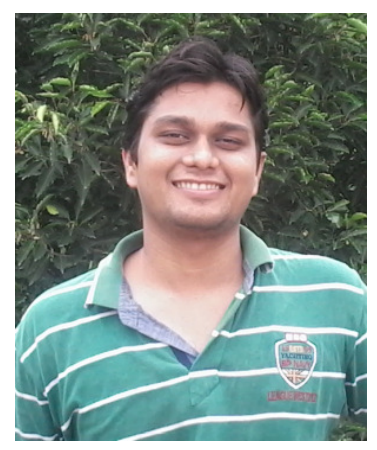

Rajesh H. Vekariya obtained his B.Sc. Degree in Chemistry in 2010 and his M.Sc. Degree in organic chemistry in 2012 both from the Gujarat University, Ahmedabad (India). Currently, he is pursuing his Ph.D. under the guidance of Dr. Hitesh D. Patel at the Chemistry Department of the Gujarat University, Ahmedabad. His research focuses on the synthesis of organic intermediates via green chemistry and their utilization in the synthesis of biologically active compounds. His research focuses on synthesis of industrially important organic intermediates by step down process and development of more eco-friendly and economical methods. $\mathrm{He}$ is working on highly important and basic industrial processes such as nitration, bromination, oxidation and reduction. 